\title{
Populasi Serangga Hama dan Artropoda Predator pada Padi Rawa Lebak Sumatera Selatan yang Diaplikasikan Bioinsektisida dari Beauveria bassiana dan Insektisida Sintetik
}

\author{
Population of Pest Insects and Predatory Arthropods Inhabiting Freshwater Swamp Rice \\ of South Sumatra Treated with Bioinsectide of Beauveria bassiana and a Synthetic \\ Insecticide
}

\author{
Khoirul Ikhsanudin Hanif ${ }^{1}$, Siti Herlinda ${ }^{2,3 *}$, Chandra Irsan ${ }^{2,3}$, Tili Karenina ${ }^{4}$, Erise \\ Anggraini $^{2,3}$, Suwandi Suwandi ${ }^{2,3}$, Susilawati Susilawati ${ }^{5}$ \\ ${ }^{1}$ Program Magister Ilmu Tanaman, Fakultas Pertanian, Universitas Sriwijaya, \\ Palembang 30139 \\ ${ }^{2}$ Jurusan Hama dan Penyakit Tumbuhan, Fakultas Pertanian, Universitas Sriwijaya, \\ Indralaya 30662 \\ ${ }^{3}$ Pusat Unggulan Riset Pengembangan Lahan Suboptimal (PUR-PLSO), Universitas \\ Sriwijaya, Palembang 30139 \\ ${ }^{4}$ Program Doktor Ilmu Pertanian, Fakultas Pertanian, Universitas Sriwijaya, \\ Palembang 30139 \\ ${ }^{5}$ Jurusan Budidaya Pertanian, Fakultas Pertanian, Universitas Sriwijaya, Indralaya 30662 \\ ${ }^{*}$ Penulis untuk korespondensi: sitiherlinda@ unsri.ac.id
}

\begin{abstract}
Entomopathogenic fungi, Beauveria bassiana, could kill various species of insect pests, but their impact on predatory arthropods needs to be studied. The aim of this study was to compare population of pest insects and predatory arthropodsinhabiting rice sprayed with bioinsecticide of $B$. bassiana and conventional rice field using a synthetic insecticides. Bioinsecticide was made from conidia of $B$. bassiana and sprayed on rice canopy. The plot of conventional farmers was sprayed with synthetic insecticides made from Abamektrin. The results showed that the application of bioinsecticide of $B$. bassiana was not proven to reduce the pest insect population. The abundance of natural enemies of pest insects, such as spiders and predatory insects was also more abundant in plots sprayed with bioinsecticide than conventional plots that used synthetic insecticide. The synthetic insecticides have been shown to reduce the abundance of predatory insects and spiders. Bioinsecticides containing carrier of liquid compost were proven to increase the growth and development of rice, which was an increase in the number of rice tillers per clump in plots applied by bioinsecticide. Thus, B. bassiana of bioinsecticide with liquid compost carrier material was safer and could maintain the abundance of predatory arthropods and increased rice growth.
\end{abstract}

Keywords: predatory arthropods, rice tillers, spider

\section{ABSTRAK}

Jamur entomopatogen, Beauveria bassiana telah terbukti dapat mematikan berbagai jenis serangga hama, namun informasi dampaknya terhadap artropoda predator perlu diteliti. Penelitian ini bertujuan untuk membandingkan populasi serangga hama dan 
artropoda predator pada padi ratun yang diaplikasikan bioinsektisida dari B. bassiana dan konvensional (insektisida sintetik).Bioinsektisida dibuat dari konidia B. bassiana dan disemprotkan pada tajuk padi. Lahan petani konvensional disemprotkan dengan insektisida sintetik berbahan aktif abamektrin. Hasil penelitian menunjukkan bahwa aplikasi bioinsektisida dari $B$. bassiana tidak terbukti menurunkan populasi serangga hama. Kelimpahan musuh alami serangga hama dari kelompok laba-laba dan serangga predator juga lebih melimpah pada petak yang diaplikasikan bioinsektisida dibandingkan petak konvensional yang menggunakan insektisida sintetik. Insektisida sintetik terbukti dapat menurunkan kelimpahan serangga predator dan laba-laba. Bioinsektisida dengan bahan pembawa kompos cair ini terbukti dapat meningkatkan pertumbuhan dan perkembangan padi, yaitu terjadi peningkatan jumlah anakan padi per rumpun di petak yang diaplikasikan bioinsektisida. Dengan demikian, bioinsektisida B. bassiana dengan bahan pembawa kompos cair lebih aman dan dapat mempertahankan kelimpahan artropoda predator dan meningkatkan pertumbuhan padi.

Kata kunci: serangga predator, anakan padi, laba-laba

\section{PENDAHULUAN}

Permasalahan dalam meningkatkan produksi padi di sawah rawa lebak Sumatera Selatan melalui peningkatan indeks pertanaman adalah pengelolaan air di musim tanam kedua (Harun et al., 2014). Penanam padi ratun dapat mengatasi permasalahan genangan air di sawah rawa lebak ini karena padi ratun dapat mempersingkat waktu tanam hanya berkisar 2 bulan (Herlinda et al., 2014; 2015a, b).

Dalam rangka meningkatkan produksi padi dapat dilakukan dengan penggunaan varietas dan galur tipe baru (Susilawati et al., 2010). Peningkatan input produksi pada padi dapat juga meningkatkan kebugaran (Islam et al., 2008). Pemupukan N yang dikombinasikan dengan $\mathrm{P}$ atau $\mathrm{K}$ padi juga dapat meningkatkan produksi padi (Susilawati et al., 2012a,b).Teknologi ekstrak kompos cair telah terbukti dapat meningkatkan kebugaran berbagai tanaman sayuran (Suwandi, 2004) dan juga dapat mengendalikan penyakit yang menyerang padi di rawa pasang surut (Kartohardjono 2011; Suwandi et al., 2012). Untuk mengendalikan serangga hama Herlinda et al (2012) telah berhasil memanfaatkan jamur entomopatogen, seperti Beauveria bassiana untuk mengendalikan kutudaun (Herlinda 2010; Herlinda et al., 2010), serangga hama padi (Herlinda et al. 2008a,b,c). Penelitian ini bertujuan untuk membandingkan populasi serangga hama dan artropoda predator pada padi ratun yang diaplikasikan bioinsektisida dari Beauveria bassiana dan konvensional (insektisida sintetntik).

\section{BAHAN DAN METODE}

Penelitian ini telah dilaksanakan pada bulan Mei hingga September 2018 di lahan padi rawa lebak, Desa Pelabuhan Dalam, Kecamatan Pemulutan, Kabupaten Ogan Ilir, Sumatera Selatan yang merupakan sentra sawah rawa lebak. Plot perlakuan dibagi dua kelompok petani, yaitu kelompok yang mengaplikasikan bioinsektisida dan yang konpensional menggunakan insektisida sintetik. Masingmasing petak luasnya $1000-1200 \mathrm{~m}^{2}$ yang diulang lima kali.

\section{Persiapan Lahan, Penanaman dan Pemeliharaan Padi}

Pengolahan tanah dilakukan dengan menggunakan bajak singkal, setelah diolah dibersihkan dari gulma dan tunggul-tunggul sisa tumbuhan. Lalu, dipupuk dengan pupuk kandang dengan dosis 1 ton/ha. Benih padi yang digunakan bersertifikat label ungu adalah varietas Mekongga dengan dosis sebanyak $50 \mathrm{~kg} / \mathrm{ha}$. Padi ditanam mengikuti kebiasaan petani setempat, yaitu sistem pindah tanam (tapin). 
Bibit bila telah berumur 7 hari dipindahkan dari persemaian untuk ditandur di sawah. Bibit padi ditandur sebanyak 2 batang per lobang dengan jarak tanam sistem tanam jajar legowo tipe $2: 1(12,5 \mathrm{~cm}$ x $25 \mathrm{~cm}$ x 50 $\mathrm{cm})$.

Pemeliharaan padi dilakukan berupa penyulaman bibit padi, pengairan, sanitasi, dan pemupukan. Penyulaman terhadap padi yang mati dilakukan saat 7 hari setelah tandur (hst). Pengairan dilakukan dengan sistem pompanisasi. Sanitasi lahan dilakukan pada fase vegetatif dan generatif dengan cara menyiangi gulma menggunakan arit. Pemupukan dilakukan dengan ekstrak kompos kulit udang yang dibuat mengikuti metode Suwandi et al (2012). Ekstrak kompos cair tersebut diaplikasikan setiap 2 minggu sekali mulai dari 14 hst sampai menjelang panen dengan dosis 2 L/ha. Pupuk Nitrogen diaplikasikan pada saat padi berumur 30 hst dengan dosis $100 \mathrm{~kg} / \mathrm{ha}$.

\section{Pembuatan dan Aplikasi Bioinsektisida}

$B$. bassiana yang digunakan pada penelitian ini hasil eksplorasi dari tanah lebak Sumatera Selatan. Identifikasi jamur dilakukan oleh Dr. Suwandi. B.bassiana terlebih dahulu diperbanyak pada media padat, Sabouraud Dextrose Agar (SDA) mengikuti metode Herlinda et al (2010). Lalu, biakan B. bassiana dari media SDA yang berumur 10 hari ini dibiakkan di media cair, Sabouraud Dextrose Broth (SDB). Biakan jamur pada SDB ini diinkubasikan di atas shaker yang digerakkan pada kecepatan $120 \mathrm{rpm}$ selama 7 x 24 jam. Lalu, biakan jamur dari media cair tersebut digunakan untuk membuat bioinsektisida. Sebelum dibuat formulasi, biakan jamur ini dihitung kerapatan sporanya, bila telah mencapai minimal $1 \mathrm{x}$ $10^{9}$ spora. $\mathrm{mL}^{-1}$ baru dibuat formulasi bioinsektisida cair. Bioinsektisida cair dibuat dengan menggunakan bahan pembawa (carrier) ekstrak kompos kulit udang, sedangkan bahan aktifnya adalah kultur cair B. bassiana, dan ditambah minyak sayur. Untuk 1 L bioinsektisida dari B. Bassiana mengandung $400 \mathrm{~mL}$ ekstrak kompos kulit udang, 600 mL biakan cair B. bassiana, dan $10 \mathrm{~mL}$ minyak sayur. Ekstrak kompos yang digunakan terlebih dahulu disterilkan pada aautoclave selama 2 jam dengan tekanan 1 atm.

Bioinsektisida disemprotkan pada tajuk padi dengan dosis $2{\mathrm{~L} / h a^{-1}}$ per aplikasi. Aplikasi dimulai saat padi berumur 13, 27, 41, 55, 69, dan 83 hst. Aplikasi bioinsektisida dilakukan pada sore hari pukul 16.00-18.00 WIB untuk mencegah spora mati terkena ultra violet. Lahan petani konvensional disemprotkan dengan insektisida sintetik berbahan aktif Abamektrin menggunakan dosis sesuai kebiasaan mereka, yaitu 0.5 L.ha ${ }^{-1}$. Insektisida sintetik tersebut disemprotkan bersamaan waktu dengan aplikasi bioinsektisida. Sawah petani konvensional ini terpisah sejauh $50 \mathrm{~m}$ dari lahan bioinsektisida. Sehari setelah aplikasi bioinsektisida dan insektisida sintetik tersebut dilakukan Pengambilan contoh arthropods di tajuk padi.

\section{Pengambilan Contoh Artropoda di Tajuk Tanaman dan Pengamatan Kebugaran Padi}

Pengambilan contoh artopoda penghuni tajuk padi menggunakan jaring serangga mengikuti metode Herlinda et al (2008c). Jaring yang digunakan memiliki panjang tangkai jaring $100 \mathrm{~cm}$, panjang jaring $75 \mathrm{~cm}$, dan diameter jaring $30 \mathrm{~cm}$. Pengambilan contoh dilakukan saat padi berumur 2,4,6,8,10, dan 12minggu setelah tanam (mst). Pengambilan contoh artopoda tsb dilakukan di pagi hari jam 06.00-07.00 WIB. Pengamatan kebugaran padi dilakukan setiap 2 minggu sekali. Tanaman contoh diamati lima rumpun yang tersebar di petak contoh. Setiap rumpun dihitung jumlah anak per rumpun dan tinggi tanaman. Artopoda yang didapat, lalu dibersihkan dan dimasukkan ke dalam botol plastik (volume $330 \mathrm{ml}$ ) yang berisi $100 \mathrm{~mL}$ etanol absolut dan diberi label. Botol berisi artopoda tersebut selanjutnya dibawa ke Laboratorium Entomologi, Jurusan Hama 
dan Penyakit Tumbuhan, Fakultas Pertanian Universitas Sriwijaya untuk diidentifikasi. Identifikasi laba-laba menggunakan acuan Barrion and Litsinger (1995) dan identifikasi serangga menggunakan acuan buku Heinrichs (1994) dan Kalshoven (1981).

\section{Analisis Data}

Data spesies artopoda dikelompokkan menjadi serangga hama, serangga predator, dan laba-laba dan ditampilkan dalam bentuk grafik.

\section{HASIL}

Hasil penelitian ini menunjukkan populasi serangga hama di petak sawah yang diaplikasikan bioinsektisida lebih tinggi dibandingkan dengan petak yang diaplikasikan insektisida sintetik yang di petak konvensional (Gambar 1). Dari sejak awal tanam hingga menjelang panen, serangga hama di petak konvensional yang menggunakan insektisida sintetik ini telah rendah dan populasi selalu tertekan. Untuk petak yang diaplikasikan bioinsektisida populasi serangga hama selalu di atas petak konvensional.

Fenomena seperti populasi serangga hama yang tinggi di petak yang diaplikasikan bioinsektisida, terjadi juga untuk kelimpahan atau populasi serangga predator (Gambar 2) dan laba-laba (Gambar 3). Kedua kelompok predator serangga hama padi ini dari sejak awal tanam hingga menjelang panen selalu lebih tinggi dibandingkan kelimpahannya di petak konvensional yang menggunakan insektisida sintetik. Dari data ini terbukti insektisida sintetik dapat menurunkan kelimpahan artropoda bukan sasaran (nontarget), yaitu serangga predator dan labalaba.

Walaupun di petak yang diaplikasikan bioinsektisida, populasi serangga hama selalu tinggi, namun tidak berdampak terhadap penurunan jumlah anakan dan tinggi tanaman padi (Gambar 4). Pertumbuhan dan perkembangan padi bahkan lebih baik di petak yang diaplikasikan bioinsektisida. Bahkan, jumlah anakan padi di petak yang diaplikasikan bionsektisida lebih banyak dibandingkan di petak konvensional yang menggunakan insektisida sintetik. Dengan demikian, bioinsektisida dengan bahan pembawa kompos cair ini terbukti dapat meningkatkan pertumbuhan dan perkembangan padi, yaitu terjadi peningkatan jumlah anakan padi per rumpun di petak yang diaplikasikan bioinsektisida.

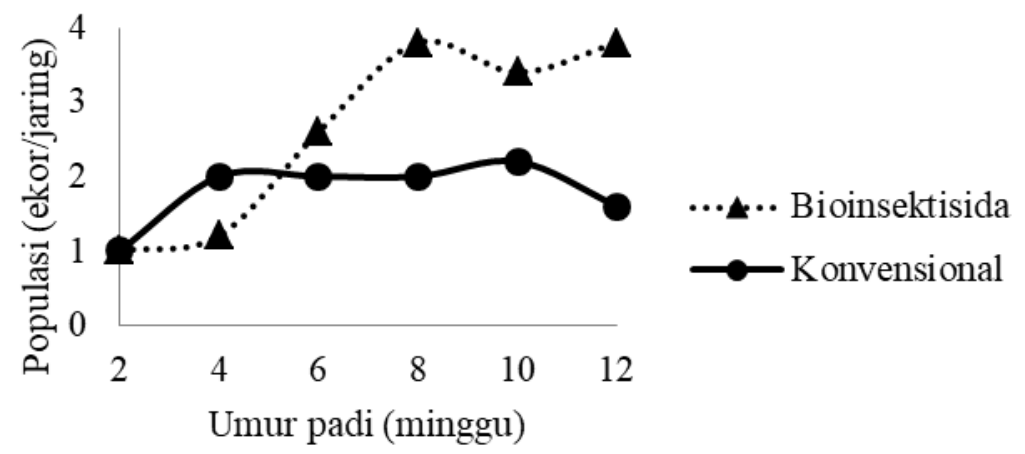

Gambar 1. Fluktuasi populasi serangga fitofag pada padi yang diaplikasikan bioinsektisida dan yang dibudidayakan secara konvensional 


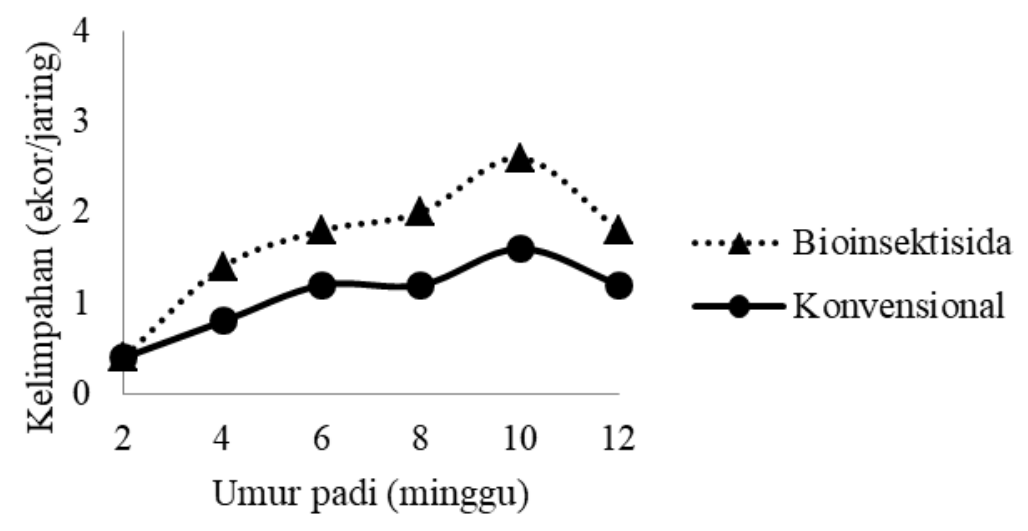

Gambar 2. Fluktuasi kelimpahan serangga predator pada padi yang diaplikasikan bioinsektisida dan yang dibudidayakan secara konvensional

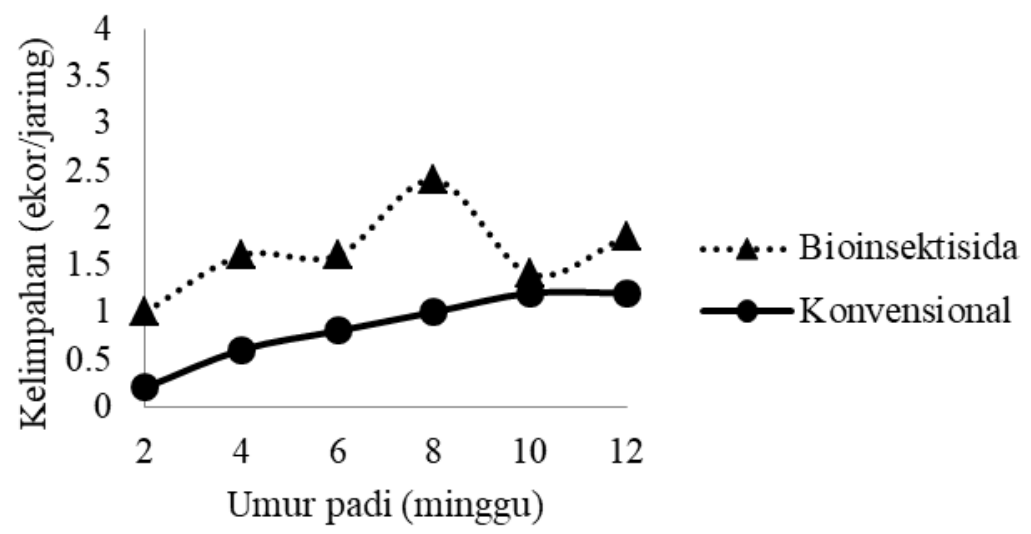

Gambar 3. Kelimpahan laba-laba pada padi yang diaplikasikan bioinsektisida dan disemprot dengan insektisida sintetik (konvensional)
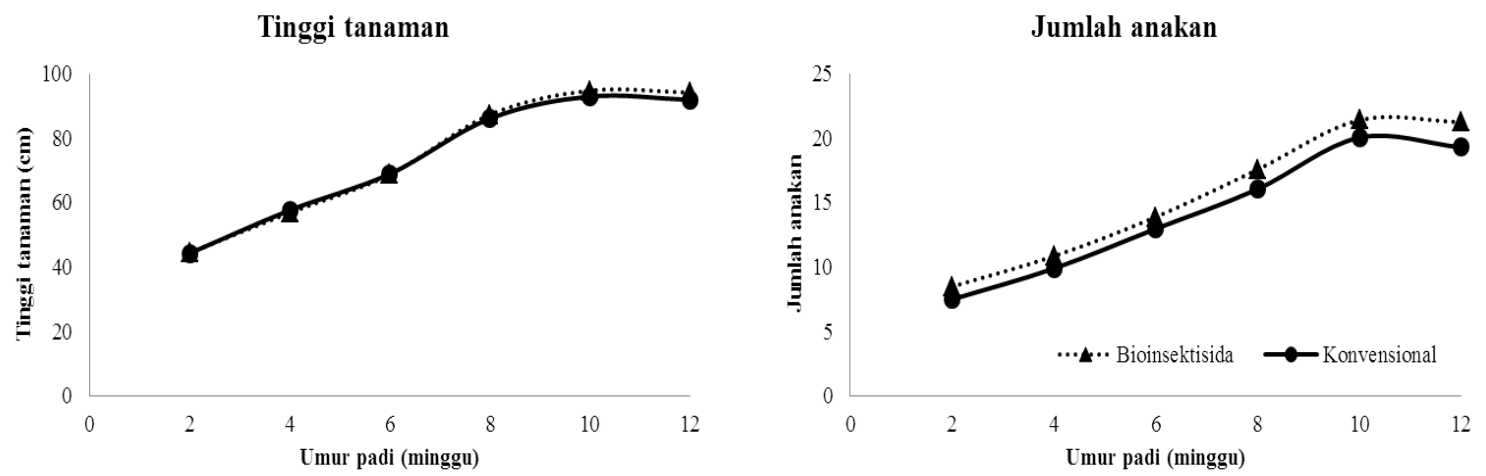

Gambar 4. Tinggi tanaman dan jumlah anakan tanaman padi yang diaplikasikan bioinsektisida dan insektisida sintetik di petak konvensional 


\section{PEMBAHASAN}

Pada penelitian ini insektisida sintetik lebih mampu menekan populasi serangga hama dibandingkan bioinsektisida dari jamur entomopatogen. Walau bioinsektisida dari $B$. bassiana telah terbukti mematikan serangga hama di laboratorium (Herlinda et al,. 2008a; 2008b; 2008c; Safitri et al., 2018), namun di lapangan banyak kendala yang menyebabkan efektifitas jamur entomopatogen lebih rendah bila dibandingkan insektisida sintetik, Surtikanti dan Yasin (2009) menyatakan bahwa faktor lingkungan seperti suhu tinggi dan kelembaban rendah dapat menurunkan kemampuan jamur entomopatogen menginfeksi serangga inang. Jamur entomopatogen untuk dapat berkecambah memerlukan keadaan yang lembab (Suprayogi et al., 2015).

Kemampuan membunuh yang terlalu tinggi dan spektrum lebar (broad spectrum) dari suatu insektisida sintetik dapat menurunkan populasi atau kelimpahan atropoda bukan sasaran (Phamet al., 2009). Penggunaan insektisida sintetik perlu dihindari di ekosistem yang telah memiliki kelimpahan artropoda musuh alami yang tinggi, seperti di sawah rawa lebak Sumatera Selatan ini. Menurut Herlinda et al.,(2018) kekayaan spesies dan kelimpahan artropoda predator, terutama laba-laba tinggi di sawah lebak Sumatera Selatan sehingga keberadaan musuh alami tersebut sudah cukup untuk menjaga kestabilan ekosistem padi dan mampu menekan populasi serangga hama. Menurunnya kelimpahan serangga predator dan laba-laba di petak yang diaplikasikan insektisida sintetik telah banyak dilaporkan peneliti sebelumnya (Azod et al., 2016; Baehaki et al., 2017). Hal ini disebabkan serangga predator dan laba-laba lebih peka terhadap insektisida sintetik bila dibandingkan dengan serangga hama, sedangkan bioinsektisida dari jamur entomopatogen tidak membahayakan artropoda predator (Firouzbakhtet al., 2015; Gholamzadeh-Chitgar et al., 2017).

\section{KESIMPULAN}

Aplikasi bioinsektisida dari $B$. bassiana tidak terbukti menurunkan populasi serangga hama, namun kelimpahan musuh alami serangga hama dari kelompok laba-laba dan serangga predator lebih melimpah pada petak yang diaplikasikan bioinsektisida dibandingkan petak konvensional yang menggunakan insektisida sintetik. Insektisida sintetik terbukti dapat menurunkan kelimpahan serangga predator dan laba-laba. Bioinsektisida dengan bahan pembawa kompos cair ini terbukti dapat meningkatkan pertumbuhan dan perkembangan padi, yaitu terjadi peningkatan jumlah anakan padi per rumpun di petak yang diaplikasikan bioinsektisida.

\section{UCAPAN TERIMA KASIH}

Penelitian ini didanai oleh Program Kemitraan Masyarakat (PKM), Direktorat Riset dan Pengabdian Masyarakat, Direktorat Jenderal Penguatan Riset dan Pengembangan, Kementerian Riset, Teknologi, dan Pendidikan Tinggi. Sesuai dengan Perjanjian Pendanaan Pelaksanaan Program Pengabdian Masyarakat, Nomor: 002/SP2H/PPM/DRPM/2018, tanggal 9 Maret 2018.

\section{DAFTAR PUSTAKA}

Azod F, Shahidi NS, Mahdian K, Smagghe G. 2016. Lethal and sublethal effects of spirotetramat and abamectin on predatory beetles Menochilus sexmaculatus via prey Agonoscena pistaciae exposure, important for integrated pest management in pistachio orchards. Belgian J. Zoology. 146 (2):113122. 
Barrion A, Litsinger J. 1995. Riceland Spiders of South and Southeast Asia. Entomology Division International Rice Research Institute Philippines.

Baehaki SE, Surahmat EC, Susetyo A, Senn R. 2017. Toxicity and persistence of insecticides to rove beetle Paederus fuscipes and wolf spider Lycosa pseudoannulata using semi field method. J. Agriculture and Veterinary Sciences. 4(9): 331-337.

Firouzbakht H, Zibaee A, Hoda H, Sohani MM. 2015. Virulence determination of Beauveria bassiana isolates on a predatory Hemipteran, Andrallus spinidens Fabricius (Hemiptera: Pentatomidae). Acta Phytopathologica et Entomologica Hungarica. 50(1):115-125.

Gholamzadeh-Chitgar M, Hajizadeh J, Ghadamyari M, Karimi-Malati A, Hoda H. 2017. Effect of sublethal concentration of Beauveria bassiana fungus on demographic and some biochemical parameters of predatory bug, Andrallus spinidens Fabricius (Hemiptera: Pentatomidae) in laboratory conditions. Trakia Journal of Sciences. 15(2):160-167.

Harun MU, Saleh E, Irsan C. 2014. Sistem Tanam Padi Kontinyu di Lahan Rawa Lebak, hal. 806-811. Dalam Herlinda et al. (eds.). Prosiding Seminar Nasional Lahan Suboptimal 2014, Palembang 26-27 September 2014.

Heinrichs EA. 1994. Biology and Management of Rice Insect. International Rice Research Intitute, Philippines.

Herlinda S, Mulyati SI, Suwandi. 2008a. Jamur entomopatogen untuk mengendalikan wereng coklat pada tanaman padi. Agritrop 27(3):119126.

Herlinda S, Mulyati SI, Suwandi. 2008b. Selection of isolates of entomopathogenic fungi, and the bioefficacy of their liquid production against Leptocorisa oratorius Fabricius nymphs. Microbiology Indonesia. 2(3):141145.

Herlinda S, Waluyo, Estuningsih SP, Irsan C. 2008c. Perbandingan keanekaragaman spesies dan kelimpahan artopodaa predator penghuni tanah di sawah lebak yang diaplikasi dan tanpa aplikasi insektisida. J. Entomol. Indon. 5(2):96-107.

Herlinda S, Darmawan KA, Adam T, Irsan C, Thalib R. 2012. Bioesai Bioinsektisida Beauveria bassiana dari Sumatera Selatan terhadap Kutu Putih Pepaya (Paracoccus marginatus). J. Entomol. Indon. 9(2):81-87.

Herlinda S, Irsan C, Mayasari R, Septariani S. 2010. Identification and Selection of Entomopathogenic Fungi as Biocontrol Agents for Aphis gossypii from South Sumatra. Microbiology Indonesia. 4(3):137142.

Herlinda S. 2010. Spore density and viability of entomopathogenic fungal isolates from Indonesia, and its virulence against Aphis gossypii Glover Homoptera: Aphididae). Tropical Life Sciences Research. 21(1):13-21.

Herlinda S, Manalu HCN, Aldina RF, Suwandi, Wijaya A, Khodijah, \& Meidalima D. 2014. Kelimpahan dan keanekragaman spesies labalaba predator hama padi ratun di sawah pasang surut. J. HPT Tropika 14(1):1-7.

Herlinda S, Kusuma A, Suwandi, Wijaya A. 2015a. Perbandingan efek pemberian bioinsektisida dan ekstrak kompos terhadap produksi padi ratun dan populasi serangga hama. Jurnal Agronomi Indinesia. 43(1):23-28

Herlinda S, Dewi R, Adam T, Suwandi, Wijaya A. 2015b. Struktur 
komunitas laba-laba di ekosistem padi ratun: pengaruh aplikasi Beauveria bassiana (Balsamo). J.Entomol.Indones. 12(2):91-99.

Herlinda S, Yudha S, Thalib R, Khodijah, Suwandi, Lakitan B, Verawaty M. 2018. Species richness and abundance of spiders inhabiting rice in fresh swamps and tidal lowlands in South Sumatra, Indonesia. Journal ISSAAS. 24 (1): 82-93.

Islam MS, Hasannuzzaman M, Rukonuzzaman M. 2008. Ratoon rice response to different fertilizer doses in irrigated condition. Agric. Conspect. Sci. 73:197-202.

Kalshoven LG. 1981. The Pest of Crops in Indonesia. Van Hoeve, Jakarta.

Kartohardjono A. 2011. Penggunaan musuh alami sebagai komponen pengendalian hama padi berbasis ekologi. Pengembangan Inovasi Pertanian. 4(1):29-46.

Pham TA, Kim JJ, Kim SG, Kim K. 2009. Production of blastospore of entomopathogenic Beauveria bassiana in a submerged batch culture. Mycobiology. 37(3): 218-224.

Safitri A, Herlinda S, Setiawan A. 2018. Entomopathogenic fungi of soils of freshwater swamps, tidal lowlands, peatlands, and highlands of South Sumatra, Indonesia. Biodiversitas 19(6): 2365-2373.

Suprayogi, Marheni, Syahrial O. 2015. Uji Efektifitas Jamur Entomopatogen Beauveria bassiana dan Metarhizium anisopliae terhadap Kepik Hijau (Nezara viridula L.)
(Hemiptera; Pentatomidae) pada Tanaman Kedelai (Glycine $\max \mathrm{L}$.) di Rumah Kasa. Jurnal Online Agroekoteknologi. 3(1):320-327.

Surtikanti, Yasin M. 2009. Keefektifan Entomopatogenik Beauveria bassiana Vuill. Dari Berbagai Media Tumbuh terhadap Spodoptera litura F. (Lepidoptera :Noctuidae) di Laboratorium. Balai Penelitian Tanaman Serelia. Prosiding Seminar Nasional Serelia.

Susilawati BS, Purwoko, Aswidinnoor $\mathrm{H}$, Santosa E. 2012a. Peran hara N, P dan $\mathrm{K}$ pada pertumbuhan dan perkembangan ratun lima genotipe padi. J. Agron. Indonesia. 40:174179.

Susilawati BS, Purwoko, Aswidinnoor H, Santosa E. 2010. Keragaan varietas dan galur padi tipe baru Indonesia dalam sistem ratun. J. Agron. Indonesia. 38: 177-184.

Susilawati BS, Purwoko, Aswidinnoor H, Santosa E. 2012b. Tingkat produksi ratun berdasarkan tinggi pemotongan batang padi sawah saat panen. J. Agron. Indonesia. 40:1-7.

Suwandi. 2004. Effectiveness of shrimps shell compost extract for suppression of leaf diseases on cowpea, chili pepper and cabbage. Pest Tropical Journal. 1(1):18-25.

Suwandi, Ammar M, Irsan C. 2012. Application of extract compost increased yield and suppressed the diseases of ratoon rice crop in tidal swamp of Banyuasin Regency. $J$. Lahan Suboptimal. 1(2):116-122. 